\title{
General Anesthesia versus Conscious Sedation in Mechanical Thrombectomy
}

\author{
Katharina Feil,, ${ }^{\mathrm{a}, \mathrm{b}}$ Moriz Herzberg, ${ }^{\mathrm{c}, \mathrm{d}}$ Franziska Dorn, ${ }^{\mathrm{c}}$ Steffen Tiedt, ${ }^{\mathrm{e}}$ Clemens Küpper, ${ }^{\mathrm{a}}$ \\ Dennis C. Thunstedt, ${ }^{\mathrm{a}}$ Ludwig C. Hinske, ${ }^{\mathrm{f}, \mathrm{g}}$ Konstanze Mühlbauer, ${ }^{\mathrm{f}}$ Sebastian Goss, ${ }^{\mathrm{f}}$ Thomas Liebig, ${ }^{\mathrm{c}}$ \\ Marianne Dieterich, ${ }^{\text {a,h,i }}$ Andreas Bayer, ${ }^{\mathrm{f}}$ Lars Kellert, ${ }^{\mathrm{a}}$ on Behalf of the GSR Investigators \\ aDepartment of Neurology, Ludwig Maximilian University (LMU), Munich, Germany \\ bDepartment of Neurology \& Stroke, Eberhard-Karls University of Tübingen, Tübingen, Germany \\ Institute of Neuroradiology, Ludwig Maximilian University (LMU), Munich, Germany \\ ${ }^{d}$ Department of Radiology, University Hospital Würzburg, Würzburg, Germany \\ 'Institute for Stroke and Dementia Research, Ludwig Maximilian University (LMU), Munich, Germany \\ fDepartment of Anesthesiology, Ludwig Maximilian University (LMU), Munich, Germany \\ ${ }^{9}$ The Institute for Medical Information Biometry and Epidemiology (IBE), Ludwig Maximilian University (LMU), Munich, Germany \\ ${ }^{h}$ Munich Cluster for Systems Neurology (SyNergy), Munich, Germany \\ 'German Center for Vertigo and Balance Disorders, Ludwig Maximilian University (LMU), Munich, Germany
}

Background and Purpose Anesthesia regimen in patients undergoing mechanical thrombectomy (MT) is still an unresolved issue.

Methods We compared the effect of anesthesia regimen using data from the German Stroke Registry-Endovascular Treatment (GSR-ET) between June 2015 and December 2019. Degree of disability was rated by the modified Rankin Scale (mRS), and good outcome was defined as mRS 0-2. Successful reperfusion was assumed when the modified thrombolysis in cerebral infarction scale was $2 b-3$.

Results Out of 6,635 patients, 67.1\% ( $n=4,453)$ patients underwent general anesthesia (GA), 24.9\% $(n=1,650)$ conscious sedation (CS), and 3.3\% ( $n=219)$ conversion from CS to GA. Rate of successful reperfusion was similar across all three groups ( $83.0 \%$ vs. $84.2 \%$ vs. $82.6 \%, P=0.149$ ). Compared to the CA-group, the GA-group had a delay from admission to groin (71.0 minutes vs. 61.0 minutes, $P<0.001$ ), but a comparable interval from groin to flow restoration (41.0 minutes vs. 39.0 minutes). The CS-group had the lowest rate of periprocedural complications ( $15.0 \%$ vs. $21.0 \%$ vs. $28.3 \%$, $P<0.001)$. The CS-group was more likely to have a good outcome at follow-up (42.1\% vs. $34.2 \%$ vs. $33.5 \%, P<0.001)$ and a lower mortality rate $(23.4 \%$ vs. $34.2 \%$ vs. $26.0 \%, P<0.001)$. In multivariable analysis, GA was associated with reduced achievement of good functional outcome (odds ratio [OR], $0.82 ; 95 \%$ confidence interval $[\mathrm{Cl}], 0.71$ to $0.94 ; P=0.004)$ and increased mortality $(\mathrm{OR}, 1.42$; $95 \% \mathrm{Cl}, 1.23$ to $1.64 ; P<0.001)$. Subgroup analysis for anterior circulation strokes $(n=5,808)$ showed comparable results.

Conclusions We provide further evidence that CS during MT has advantages over GA in terms of complications, time intervals, and functional outcome.

Keywords Conscious sedation; Stroke; Reperfusion; Thrombectomy; Anesthesia; Thrombolytic therapy
Correspondence: Lars Kellert Department of Neurology, Ludwig Maximilian University (LMU) Munich, Marchioninistrasse 15, 81377 Munich, Germany

Tel: +49-89-4400-73692

Fax: +49-89-4400-76671

E-mail: Lars.Kellert@med.uni-

muenchen.de

https://orcid.org/0000-0002-4967-8336

Co-correspondence: Katharina Feil Department of Neurology \& Stroke, Eberhard-Karls University of Tübingen, Hoppe-Seyler-Strasse 6, 72076 Tübingen, Germany

Tel: +49-7071-29-61753

Fax: +49-7071-29-25297

E-mail: Katharina.feil@uni-tuebingen.de https://orcid.org/0000-0002-4566-712X

Received: June 18, 2020

Revised: September 21, 2020

Accepted: September 22, 2020 


\section{Introduction}

While mechanical thrombectomy (MT) is the standard of care in eligible patients with large vessel occlusion (LVO), the appropriate anesthesia regimen is still an unresolved issue. The primary goal of sedation management during $\mathrm{MT}$ is to enable the interventionalist to perform the procedure as quickly and safely as possible. However, studies on this topic have shown conflicting results. A recent meta-analysis from three randomized single-center trials showed an advantage for general anesthesia (GA) compared to conscious sedation (CS) in patients with anterior circulation strokes who underwent MT with respect to 3-month outcome. ${ }^{1}$ Contrary to this, a post hoc analysis from 797 patients from the Highly Effective Reperfusion Using Multiple Endovascular Devices (HERMES) Collaboration showed that patients treated without GA had a better 3-month outcome compared to those treated under GA. ${ }^{2}$ Data from another registry on anesthesia regimens with 4,429 patients showed, ${ }^{3}$ that GA was associated with worse functional outcome, especially when compared with local anesthesia. Due to the lack of evidence from large clinical trials on this topic, these results have to be interpreted with caution. The supposed advantages of GA would be the patients' immobilization during MT, proper pain management, airway protection and therefore fewer periprocedural complications. The more optimal periprocedural conditions are said to lead to higher rates of successful reperfusion resulting in better functional outcome.' On the other hand, GA may cause a delay before groin puncture and result in complications related to intensive care management leading to an overall delay in the hospital stay. Advantages of CS include clinical and neurological monitoring, fewer hemodynamic fluctuations, and potentially shorter procedures. However, unprotected airways and patient movement are believed to have a negative influence on functional outcome. Here we aimed to analyze the real-life practice of anesthesia regimen in MT-patients from the German Stroke Registry-Endovascular Treatment (GSR-ET) and its impact on complications and outcome. ${ }^{4}$

\section{Methods}

Data from the GSR-ET (https://www.clinicaltrials.gov; NCT03356392) were analyzed. Details of the registry have been published previously. ${ }^{4.5}$ See Appendix 1 for steering committee members of GSR (GSR investigators).

\section{Study population}

Between June 2015 and December 2019, 6,635 patients from 25 sites in Germany with acute ischemic stroke due to LVO, who were treated with MT, were included. The decision for MT was based on the interdisciplinary decision of treating physicians including clinical and imaging parameters and according to national (German Neurological Society) and international guidelines (European Stroke Organization, American Heart Association). ${ }^{6-8}$

Stroke severity was assessed by the National Institutes of Health Stroke Scale (NIHSS). Pre- and post-stroke disability was rated by the modified Rankin Scale (mRS). Early infarct signs were assessed by the Alberta Stroke Program Early CT Score (ASPECTS). Site of occlusion was determined by computed tomography angiography, magnetic resonance angiography, or angiography. Reperfusion success was measured by the modified thrombolysis in cerebral infarction ( $\mathrm{mTICl}$ ) scale and $\mathrm{mTICl} 2 \mathrm{~b}-3$ was rated as successful reperfusion.

The periprocedural anesthesia regimen was based on individual and interdisciplinary decisions and in-house protocols. In general, patients received either GA or CS; a small group converted from $\mathrm{CS}$ to $\mathrm{GA}$ for various periprocedural reasons. In 313 patients, the anesthesia regimen was not documented.

\section{Statistical analysis}

Continuous variables were tested for normal distribution using the Kolmogorov-Smirnov test. Normally distributed data were presented as mean \pm standard deviation and non-normally distributed data as median (interquartile range) or counts and percentages. Clinical characteristics, imaging data, periprocedural times, and outcome parameters were compared across the three groups using the Kruskal-Wallis test or median-test, as appropriate. Binary logistic regression analysis was performed for good outcome (mRS 0-2) and mortality at follow-up, including variables that were either statistically or clinically (or biologically) significant. For logistic regression analysis, categorical variables were defined as follows: sex male $=0$, female $=1$; intravenous thrombolysis treatment no $=0$, yes $=1$; successful recanalization no $=0$, yes $=1$; type of anesthesia $C S=0, G A=1$; intracerebral hemorrhage $(\mathrm{ICH})$ no $=0$, yes $=1$; tandem lesion no $=0$, yes $=1$; posterior circulation stroke no $=0$, yes $=1$; pretreatment with oral anticoagulants no $=0$, yes $=1$. Converted patients and patients with unknown anesthesia regimen were excluded from the logistic analysis. For all statistical testing, we used the SPSS version 25.0 for Windows (IBM Co., Armonk, NY, USA).

\section{Ethics}

The study was conducted in accordance with the Declaration of Helsinki and was centrally approved by the Institutional Review Board (IRB) of the Ludwig-Maximilians-Universität Munich (protocol No. 689-15). Further approval was obtained 
Table 1. Characteristics of GSR-patients comparing the anesthesia regimen ( $n=6,635$ patients, unknown in $n=313$ )

\begin{tabular}{|c|c|c|c|c|}
\hline Characteristic & $\begin{array}{c}\text { Conscious sedation } \\
(\mathrm{n}=1,650,24.9 \%)\end{array}$ & $\begin{array}{c}\text { General anesthesia } \\
(n=4,453,67.1 \%)\end{array}$ & $\begin{array}{c}\text { Conversion } \\
(\mathrm{n}=219,3.3 \%)\end{array}$ & $P$ \\
\hline Age (yr) & $73.4 \pm 13.0$ & $73.1 \pm 13.1$ & $70.3 \pm 13.3$ & 0.340 \\
\hline Female sex & $835(50.6)$ & $2,265(50.9)$ & $98(44.7)$ & 0.206 \\
\hline \multicolumn{5}{|l|}{ Clinical characteristics at admission } \\
\hline pmRS & $\begin{array}{c}0(0-1) \\
\text { (missing in } n=45)\end{array}$ & $\begin{array}{c}0(0-1) \\
\text { (missing in } n=342)\end{array}$ & $\begin{array}{c}0(0-1) \\
\text { (missing in } n=15)\end{array}$ & 0.004 \\
\hline $\mathrm{pmRS} \leq 1$ & $1,278(77.5)$ & $3,237(72.7)$ & 167 (76.3) & 0.017 \\
\hline Baseline NIHSS & $13(8-11)$ & $15(10-19)$ & $15(9-18)$ & $<0.001$ \\
\hline Drip and ship & $800(48.5)$ & $1,834(41.2)$ & 108 (49.3) & $<0.001$ \\
\hline BP systolic at admission & $154.7 \pm 27.4$ & $151.0 \pm 27.4$ & $155.5 \pm 28.0$ & $<0.001$ \\
\hline BP diastolic at admission & $84.4 \pm 17.0$ & $82.0 \pm 17.0$ & $86.0 \pm 16.0$ & $<0.001$ \\
\hline Heart rate at admission & $82.4 \pm 19.1$ & $81.5 \pm 19.2$ & $84.5 \pm 18.5$ & 0.015 \\
\hline OAC at admission & $332(20.1)$ & $896(20.1)$ & $35(16.0)$ & 0.116 \\
\hline \multicolumn{5}{|l|}{ Risk factors } \\
\hline Arterial hypertension & $1,229(74.5)$ & 3,265 (73.3) & $157(71.7)$ & $<0.001$ \\
\hline Diabetes mellitus & $342(20.7)$ & $934(21.0)$ & $46(21.0)$ & 0.119 \\
\hline Hypercholesterolemia & $532(32.2)$ & $1,753(39.4)$ & 77 (35.2) & $<0.001$ \\
\hline Current smoking & 208 (12.6) & $585(13.1)$ & 40 (18.3) & $<0.001$ \\
\hline Atrial fibrillation & $662(40.1)$ & 1,765 (39.6) & $82(37.4)$ & 0.348 \\
\hline \multicolumn{5}{|l|}{ Imaging data } \\
\hline ASPECTS & $9(7-10)$ & $9(7-10)$ & $8(7-10)$ & 0.010 \\
\hline Tandem lesion & $221(13.4)$ & 730 (16.4) & 39 (17.8) & 0.011 \\
\hline Anterior circulation & 1,572 (95.3) & $3,786(85.0)$ & 194 (88.6) & $<0.001$ \\
\hline Right-sided occlusion & $810(48.7)$ & $1,824(40.9)$ & $90(41.1)$ & 0.002 \\
\hline \multicolumn{5}{|l|}{ Type of occlusion* } \\
\hline Basilar artery & $50(3.0)$ & $556(12.5)$ & $17(7.8)$ & $<0.001$ \\
\hline Vertebral artery & $6(0.4)$ & $121(2.7)$ & $3(1.4)$ & $<0.001$ \\
\hline PCA & $30(1.8)$ & 147 (3.3) & $8(3.7)$ & 0.003 \\
\hline ACA & $35(2.1)$ & $108(2.4)$ & $3(1.4)$ & 0.521 \\
\hline Carotid-T & $250(15.2)$ & 766 (17.2) & 39 (17.8) & 0.184 \\
\hline ICA intracranial & $85(5.2)$ & $227(5.1)$ & $17(7.8)$ & 0.213 \\
\hline ICA extracranial & $132(8.0)$ & $295(6.6)$ & $16(7.3)$ & 0.144 \\
\hline MCA, proximal M1 & $529(32.1)$ & $1,346(30.2)$ & 72 (32.9) & 0.219 \\
\hline MCA, distal M1 & 394 (23.9) & 778 (17.5) & 40 (18.3) & $<0.001$ \\
\hline MCA, M2 & 361 (21.9) & $959(21.5)$ & $45(20.5)$ & 0.422 \\
\hline \multicolumn{5}{|l|}{ Time intervals (min) } \\
\hline Admission to groin & $61.0(40.0-89.0)$ & $71.0(47.0-103.0)$ & $61.0(41.0-83.0)$ & $<0.001$ \\
\hline Groin to flow restoration & $39.0(25.0-63.0)$ & $41.0(26.0-65.0)$ & $64.5(42.0-100.0)$ & $<0.001$ \\
\hline Admission to flow restoration & $107.0(76.0-143.0)$ & 118.5 (88.0-160.0) & $129.0(97.8-179.0)$ & $<0.001$ \\
\hline \multicolumn{5}{|l|}{ Treatment } \\
\hline IVT treatment & $846(51.3)$ & $2,208(49.6)$ & $129(58.9)$ & 0.018 \\
\hline $\begin{array}{l}\text { Additive medication during } \\
\text { thrombectomy }\end{array}$ & 327 (19.8) & $1,548(34.8)$ & $54(24.7)$ & $<0.001$ \\
\hline ASA & $18(1.1)$ & $92(2.1)$ & $5(2.3)$ & 0.036 \\
\hline Clopidogrel & $2(0.1)$ & $14(0.3)$ & $1(0.5)$ & 0.373 \\
\hline Ticagrelor & $0(0)$ & $21(0.5)$ & $1(0.5)$ & 0.020 \\
\hline
\end{tabular}


Table 1. Continued

\begin{tabular}{|c|c|c|c|c|}
\hline Characteristic & $\begin{array}{l}\text { Conscious sedation } \\
(n=1,650,24.9 \%)\end{array}$ & $\begin{array}{l}\text { General anesthesia } \\
(n=4,453,67.1 \%)\end{array}$ & $\begin{array}{c}\text { Conversion } \\
(n=219,3.3 \%)\end{array}$ & $P$ \\
\hline Tirofiban & $21(1.3)$ & $136(3.1)$ & $9(4.1)$ & $<0.001$ \\
\hline Abciximab & $0(0)$ & $3(0.1)$ & $1(0.5)$ & 0.040 \\
\hline Heparin & $226(13.7)$ & $1,067(24.0)$ & $33(1.4)$ & $<0.001$ \\
\hline rtPA & $47(2.8)$ & $93(2.1)$ & $6(2.7)$ & 0.194 \\
\hline $\begin{array}{l}\text { Acute treatment ipsilateral ICA } \\
\text { (stenting and/or PTA) }\end{array}$ & $169(10.2)$ & $526(11.8)$ & $25(11.4)$ & 0.110 \\
\hline No. of passages & $2.0 \pm 1.6$ & $2.2 \pm 1.8$ & $2.5 \pm 1.9$ & $<0.001$ \\
\hline Periprocedural complications & $248(15.0)$ & $934(21.0)$ & $62(28.3)$ & $<0.001$ \\
\hline Device malfunction & $9(0.5)$ & $21(0.5)$ & $2(0.9)$ & 0.995 \\
\hline Dissection, perforation & $42(2.5)$ & $130(2.9)$ & $14(6.4)$ & 0.007 \\
\hline Clot migration, embolization & $55(3.3)$ & $185(4.2)$ & $9(4.1)$ & 0.426 \\
\hline $\mathrm{ICH}$ & $29(1.7)$ & $127(2.8)$ & $13(5.9)$ & $<0.001$ \\
\hline Vasospasm & $57(3.5)$ & $389(8.7)$ & $22(10.0)$ & $<0.001$ \\
\hline Resuscitation & $8(0.5)$ & $13(0.3)$ & $2(0.9)$ & 0.070 \\
\hline Other & $110(6.7)$ & $272(6.1)$ & $23(10.5)$ & 0.003 \\
\hline Successful reperfusion mTICl $2 b / 3$ & $1,370(83.0)$ & $3,751(84.2)$ & $181(82.6)$ & 0.149 \\
\hline \multicolumn{5}{|l|}{ 24-hr follow-up } \\
\hline $\mathrm{mRS}$ & $\begin{array}{c}4(3-5) \\
\text { (missing in } n=93)\end{array}$ & $\begin{array}{c}5(3-5) \\
\text { (missing in } n=491)\end{array}$ & $\begin{array}{c}5(4-5) \\
\text { (missing in } n=32)\end{array}$ & 0.170 \\
\hline NIHSS & $8(3-16)$ & $11(4-20)$ & $13(5-23)$ & $<0.001$ \\
\hline Complications & 705 (42.7) & $2,076(46.6)$ & $117(53.5)$ & 0.002 \\
\hline Malignant MCA infarction & $69(4.2)$ & $284(6.4)$ & $15(6.8)$ & 0.001 \\
\hline Recurrent stroke & $62(3.8)$ & $264(5.9)$ & $6(2.7)$ & $<0.001$ \\
\hline $\mathrm{ICH}$ & $187(11.3)$ & $625(14.0)$ & $47(21.5)$ & $<0.001$ \\
\hline Myocardial infarction & $30(1.8)$ & $75(1.7)$ & $2(0.9)$ & 0.612 \\
\hline Groin hematoma & $34(2.1)$ & $64(1.4)$ & $7(3.2)$ & 0.406 \\
\hline Groin aneurysm & $14(0.8)$ & $30(0.7)$ & $1(0.5)$ & 0.693 \\
\hline Other complications & $426(25.8)$ & $1,278(28.7)$ & $72(32.9)$ & 0.023 \\
\hline Hospital stay (day) & $9.5 \pm 7.5$ & $11.3 \pm 9.5$ & $11.1 \pm 8.1$ & $<0.001$ \\
\hline \multicolumn{5}{|l|}{ Discharge } \\
\hline NIHSS & $4(1-11)$ & $5(2-12)$ & $6(2-13)$ & 0.022 \\
\hline $\mathrm{mRS}$ & $\begin{array}{c}3(2-5) \\
\text { (missing in } n=17)\end{array}$ & $\begin{array}{c}4(2-5) \\
\text { (missing in } n=325)\end{array}$ & $\begin{array}{c}4(2-5) \\
\text { (missing in } n=9)\end{array}$ & $<0.001$ \\
\hline Mortality (mRS 6) & $188(11.4)$ & 775 (17.4) & 27 (12.3) & $<0.001$ \\
\hline
\end{tabular}

Values are presented as mean \pm standard deviation, number (\%), or median (interquartile range).

GSR, German Stroke Registry; pmRS, pre-stroke modified Rankin Scale; NIHSS, National Institutes of Health Stroke Scale; BP, blood pressure; OAC, oral anticoagulation; ASPECTS, Alberta Stroke Program Early CT Score; PCA, posterior cerebral artery; ACA, anterior cerebral artery; ICA, internal carotid artery; MCA, middle cerebral artery; IVT, intravenous thrombolysis; ASA, acetylsalicylic acid; rtPA, recombinant tissue plasminogen activator; PTA, percutaneous transluminal angioplasty; ICH, intracerebral hemorrhage; $\mathrm{mTICl}$, modified thrombolysis in cerebral infarction; mRS, modified Rankin Scale.

*Multiple occlusion sites possible.

from local IRBs according to local regulations. Informed consent was not mandatory in accordance with the IRB approval since there were no study-specific procedures performed and data analysis of all patients undergoing MT was demanded by the governmental quality surveillance system.

\section{Results}

Out of 6,635 patients from the GSR-ET, 67.1\% $(n=4,453)$ underwent GA and $24.9 \%(n=1,650)$ CS during MT. In 3.3\% of all patients $(n=219)$, the anesthesia regimen was converted from 
Table 2. Logistic regression for periprocedural complications during mechanical thrombectomy in general anesthesia- and conscious sedation-groups

\begin{tabular}{lccc}
\hline Variable & OR & $95 \% \mathrm{Cl}$ & \\
Age & 0.99 & $0.98-0.99$ & 0.002 \\
Sex & 1.09 & $0.93-1.27$ & 0.291 \\
pmRS & 1.11 & $1.03-1.18$ & 0.004 \\
NIHSS at admission & 0.99 & $0.98-1.01$ & 0.533 \\
Treatment with IVT & 1.02 & $0.86-1.21$ & 0.840 \\
General anesthesia & 1.58 & $1.35-1.86$ & $<.001$ \\
Tandem lesion & 1.21 & $0.98-1.50$ & 0.080 \\
Posterior circulation stroke & 0.57 & $0.13-2.59$ & 0.470 \\
Time from admission to groin puncture & 1.00 & $0.99-1.00$ & 0.153 \\
ASPECTS & 1.01 & $0.96-1.05$ & 0.787 \\
No. of passages & 1.18 & $1.14-1.23$ & $<0.001$ \\
Pretreatment (OAC) & 0.78 & $0.62-0.97$ & 0.025
\end{tabular}

$\mathrm{OR}$, odds ratio; $\mathrm{Cl}$, confidence interval; pmRS, pre-stroke modified Rankin Scale; NIHSS, National Institutes of Health Stroke Scale; IVT, intravenous thrombolysis; ASPECTS, Alberta Stroke Program Early CT Score; OAC, oral anticoagulation.

initial $C S$ to $G A$, while the anesthesia regimen was not documented in 313 patients (4.7\%). The CS- and GA-groups were of similar age and sex, but patients from the GA-group had higher pre-stroke modified Rankin Scale (pmRS) and higher NIHSS on admission (Table 1). CS-patients were more often admitted via drip and ship (48.5\% vs. $41.2 \%$ vs. $49.3 \%$, $P<0.001)$. Further, the CS-group had more often patients with right-sided ( $48.7 \%$ vs. $40.9 \%$ vs. $41.1 \%, P=0.002$ ) and anterior circulation stroke $(95.3 \%$ vs. $85.0 \%$ vs. $88.6 \%, P<0.001)$. The rate of successful reperfusion was similar in all three groups ( $83.0 \%$ vs. $84.2 \%$ vs. $82.6 \%, P=0.149$ ). While tandem lesions were more frequent in the GA-group (13.4\% vs. $16.4 \%$ vs. $17.8 \%, P=0.011)$, rate of acute treatment of ipsilateral internal carotid artery (stenting and/or percutaneous transluminal angioplasty) was comparable in all groups ( $10.2 \%$ vs. $11.8 \%$ vs. $11.4 \%, P=0.110$ ). GA compared to CS was associated with a significant delay from admission to groin (61.0 minutes vs. 71.0 minutes vs. 61.0 minutes, $P<0.001)$. Time from groin to flow restoration did not differ between the GA- and the CS-groups (39.0 minutes vs. 41.0 minutes), while the converted group had a significantly longer time interval from groin to flow restoration (64.5 minutes, $P<0.001$ ). Overall, the $C S$-group showed the lowest rate of periprocedural complications (15.0\% vs. $21.0 \%$ vs. $28.3 \%, P<0.001)$.

GA was independently associated with higher periprocedural complications (odds ratio [OR], 1.58; 95\% confidence interval [Cl], 1.35 to $1.86 ; P<0.001$ ) (Table 2). In the $G A$-group, patients were more likely to receive intensive antithrombotic medications (Table 1). In the CS-group, rates of periprocedural ICH $(1.7 \%$ vs. $2.8 \%$ vs. $5.9 \%, P<0.001)$ and complications during the whole hospital stay ( $42.7 \%$ vs. $46.6 \%$ vs. $53.5 \%, P=0.002)$ were lowest. Hospital stay was significantly shorter in the CSgroup compared to GA-group and the converted group (9.5 \pm 7.5 days vs. $11.3 \pm 9.5$ days vs. $11.1 \pm 8.1$ days, $P<0.001$ ).

At 24 hours, CS patients performed better with respect to NIHSS (8 vs. 11 vs. 13, $P<0.001$ ). Three-month follow up was not available in $15.4 \%(n=1,021)$. The patients in the CS-group were more likely to achieve good outcome (42.1\% vs. $34.2 \%$ vs. $33.5 \%, P<0.001)$ and had a lower rate of mortality $(23.4 \%$ vs. $32.4 \%$ vs. $26.0 \%, P<0.001$ ) (Figure $1 A$ ).

In multivariable analysis, GA was associated with reduced achievement of good functional outcome $(\mathrm{OR}, 0.82 ; 95 \% \mathrm{Cl}$, 0.71 to $0.94 ; P=0.004)$ and increased mortality $(O R, 1.42 ; 95 \%$ $\mathrm{Cl}, 1.23$ to $1.64 ; P<0.001$ ) (Tables 3 and 4 ).

We performed an additional analysis, restricted to patients with anterior circulation strokes $(n=5,808)$ (Supplementary Table 1), which showed comparable results with respect to time delay, complications, and outcome parameters (Figure 1B and Supplementary Tables 2 and 3 ).

\section{Discussion}

Here we present by far the largest sample size on anesthesia regimens in 6,635 MT-patients with the following results: GA was the most common strategy in centers within the GSR-ET; more than two-thirds of the patients received MT under GA. The GA-rate is considerably higher than reported in data from clinical trials or registry data with about $30 \%$ of patients receiving GA (28.0\% to $37.6 \%))^{9-12}$ In about $12 \%$ of patients starting MT under $\mathrm{CS}$, a conversion to GA was necessary (cor- 
6,635 mRS score at 3-month follow-up

$0 \square 1 \square 2 \square 3 \square 4 \square 5 \square 6$

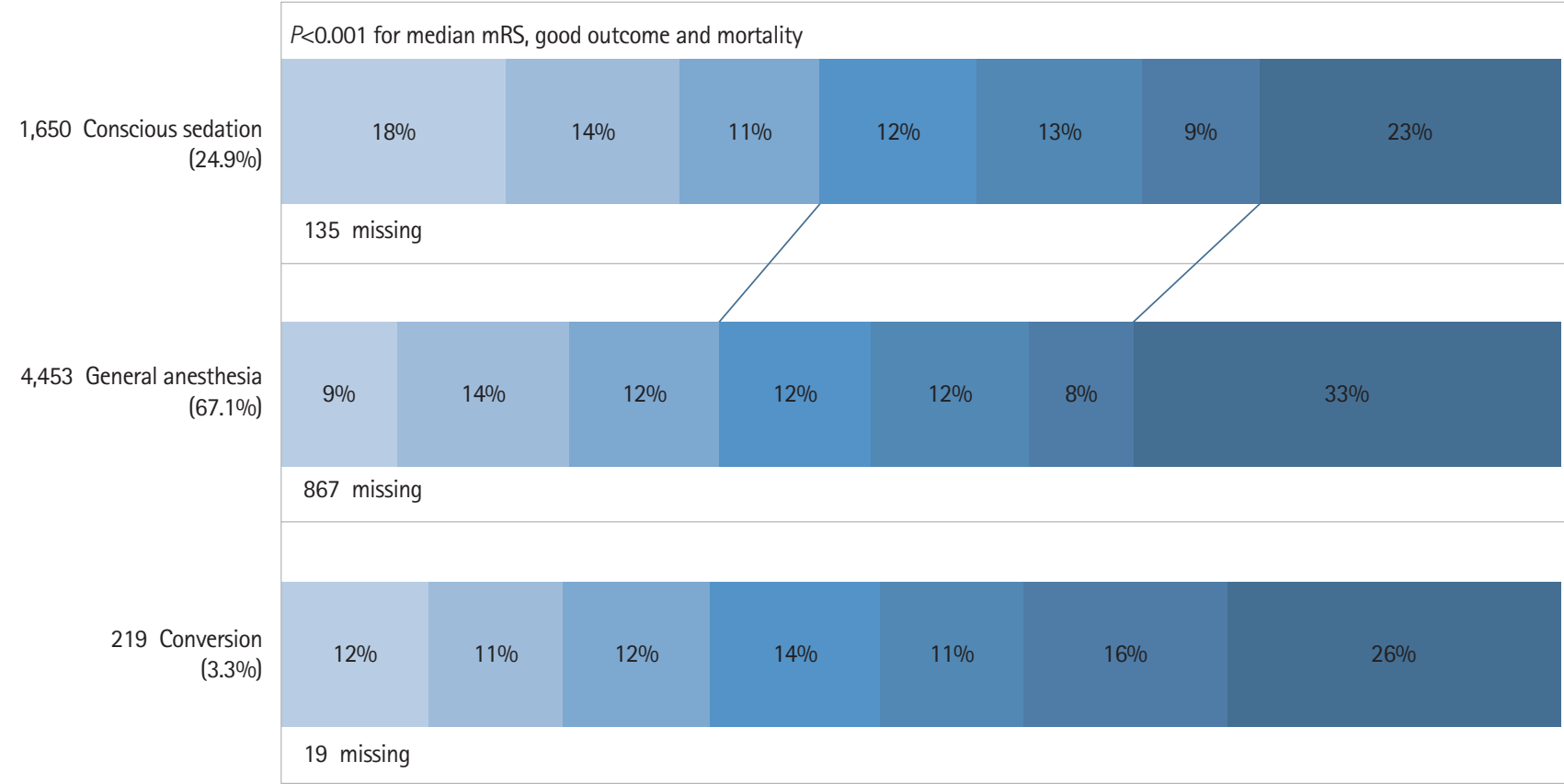

313 Anesthesia regimen unknown

1,572 Conscious sedation $(27.1 \%)$

3,786 General anesthesia $(65.6 \%)$ 194 Conversion

$$
12
$$

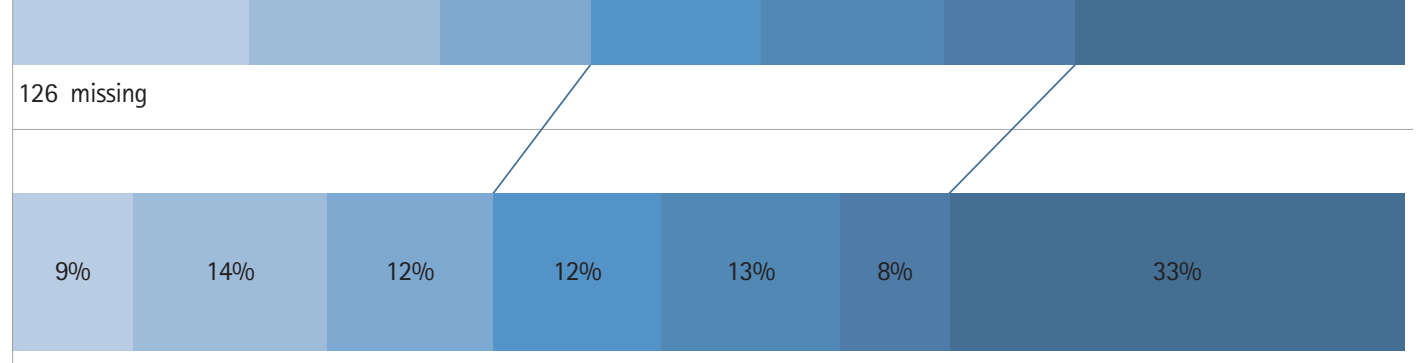

750 missing

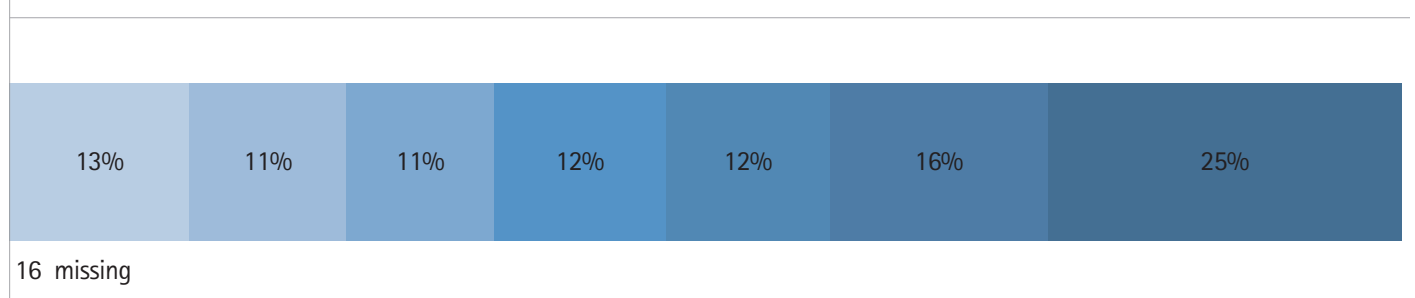

256 Anesthesia regimen unknown

Figure 1. Modified Rankin Scale (mRS) at 3-months follow-up for all large vessel occlusion stroke (A) and for anterior circulation stroke (B). Good outcome $m R S \leq 2$. 
Table 3. Logistic regression for good outcome in general anesthesia- and conscious sedation-groups at follow-up

\begin{tabular}{lccr}
\hline Variable & OR & $95 \% \mathrm{Cl}$ & \multicolumn{1}{c}{$P$} \\
Age & 0.95 & $0.95-0.96$ & $<.001$ \\
Sex & 1.01 & $0.87-1.17$ & 0.885 \\
pmRS & 0.53 & $0.49-0.58$ & $<0.001$ \\
NIHSS at admission & 0.89 & $0.88-0.90$ & $<0.001$ \\
Treatment with IVT & 1.73 & $1.50-2.00$ & $<0.001$ \\
Successful reperfusion (mTICl 2b/3) & 4.87 & $3.82-6.22$ & $<0.001$ \\
General anesthesia & 0.82 & $0.71-0.94$ & 0.004 \\
ICH & 0.26 & $0.21-0.33$ & $<0.001$ \\
Time from admission to groin & 0.99 & $0.999-1.00$ & 0.019 \\
\hline
\end{tabular}

$\mathrm{OR}$, odds ratio; $\mathrm{Cl}$, confidence interval; pmRS, pre-stroke modified Rankin Scale; NIHSS, National Institutes of Health Stroke Scale; IVT, intravenous thrombolysis; $\mathrm{mTICl}$, modified thrombolysis in cerebral infarction; ICH, intracerebral hemorrhage.

Table 4. Logistic regression for mortality in general anesthesia- and conscious sedation-groups at follow-up

\begin{tabular}{lccc}
\hline Variable & OR & $95 \% \mathrm{Cl}$ & $P$ \\
\hline Age & 1.06 & $1.05-1.07$ & $<0.001$ \\
Sex & 0.90 & $0.78-1.05$ & 0.167 \\
pmRS & 1.35 & $1.27-1.42$ & $<0.001$ \\
NIHSS at admission & 1.09 & $1.07-1.10$ & $<0.001$ \\
Treatment with IVT & 0.64 & $0.56-0.74$ & $<0.001$ \\
Successful reperfusion (mTICl 2b/3) & 0.28 & $0.24-0.34$ & $<0.001$ \\
General anesthesia & 1.42 & $1.23-1.64$ & $<0.001$ \\
ICH & 2.71 & $2.26-3.25$ & $<0.001$ \\
Time from admission to groin & 1.00 & $1.00-1.00$ & 0.114 \\
\hline
\end{tabular}

$\mathrm{OR}$, odds ratio; $\mathrm{Cl}$, confidence interval; pmRS, pre-stroke modified Rankin Scale; NIHSS, National Institutes of Health Stroke Scale; IVT, intravenous thrombolysis; mTICl, modified thrombolysis in cerebral infarction; ICH, intracerebral hemorrhage.

responding to $3 \%$ of the whole cohort). This is in line with rates that ranged from about $10 \%$ to $15 \%$ in other studies. ${ }^{13-17}$ In our study, patients from the CS-group performed better with respect to clinical outcomes at 24 hours, at discharge, and at follow-up after 3 months than patients with MT under GA.

Time intervals showed delayed start of groin puncture in GApatients and therefore longer time intervals from admission to flow restoration. Successful reperfusion rate was similar across all three patient groups. More periprocedural and in-hospital complications were observed under GA-independently of possible confounders, such as tandem lesions, posterior circulation stroke, or number of passages. The interpretation of this result remains speculative. Possibly, there are confounders we cannot address appropriately yet, such as changes in blood pressure caused by GA or imbalances in baseline parameters. Thus the regression analysis cannot appropriately adjust for all these confounders. Well-balanced groups in clinical trials would be necessary to overcome these shortcomings.

Overall, these findings are in contrast to prior studies, but in line with data from another registry analyzing 4,429 patients. ${ }^{3}$ A recent meta-analysis from three clinical trials showed an advantage of GA with respect to outcome, an effect that was most probably driven by higher rates of successful reperfusion in the GA-group. Investigators speculated that GA leads to more optimal interventional conditions, resulting in higher reperfusion rates. ${ }^{1}$ A post hoc analysis from 797 patients from the HERMES collaboration showed non-GA patients to have a higher rate of good outcome at 3 months compared to GA-patients. ${ }^{2}$ However, in this post hoc analysis only $30 \%$ of patients were treated under GA. Besides, they used data from RCTs, which were much more homogenous with respect to pmRS, baseline parameters, and occlusion side than in our study. ${ }^{2}$ Poorer outcome in the GA-group was most probably not only caused by periprocedural complications but could partly be explained by the fact that the GA- and CS-groups were not fully balanced. With respect to periprocedural complications, we observed higher rates of dissection and perforation, $\mathrm{ICH}$, and vasospasm in the GA-group and the converted group. These 
complications could have been clinical reason for conversion from $\mathrm{CS}$ to $\mathrm{GA}$.

A recent analysis from a prospective Italian registry (Italian Registry of Endovascular Treatment of Acute Stroke [IRETAS]) showed that two-thirds of these patients were treated with CS or local anesthesia. In contrast, in centers from the GSR-ET two thirds of patients underwent MT under GA. Our patients had a pmRS of 0-1 in about 80\% compared to up to 90\% in IRETAS. ASPECTS in the GSR was 8-9 and 10 in IRETAS. This might partially explain the observation of different sedation regimens. However, due to different sedation regimens and different study populations the comparability of both studies is limited. Besides, our data provide further evidence for anesthesia and sedation management, especially regarding periprocedural complications that have been less well explored using a large dataset.

Our data show significantly lower systolic and diastolic blood pressure and heart rate at admission in the GA-group. However, we have no data on the temporal changes of blood pressure data, especially a significant drop which potentially increases infarct size, leading to poor outcome. ${ }^{18}$ In the GA-group, the cumulative dose of norepinephrine-reflecting the drop in blood pressure under GA-was an independent predictor of an unfavorable outcome. ${ }^{19}$ On the other hand, vasospasm occurred most frequently under $\mathrm{GA}$. As high $\mathrm{PaO}_{2}$ is discussed to cause intracerebral vasospasm, this effect might be more likely to occur under GA than under $\mathrm{CS} .{ }^{20}$ However, our data do not allow any conclusion on causality to be drawn. Thus, the causality between GA and higher occurrence of vasospasm as a periprocedural complication is speculative. In converted patients, we neither provided information on the time of the periprocedural complication nor of the conversion from GA to CS. Therefore, we cannot conclude that the periprocedural complication rate is lower in the GA-group.

With regard to the total complication rate during the hospital stay, there were clear differences with a disadvantage of $\mathrm{GA}$, especially regarding the occurrence of $\mathrm{ICH}$ and all other complications. In the GA-group, antithrombotic medication was used more intensively. In terms of complications, rates of $\mathrm{ICH}$ were highest in patients treated under GA. In summary, patients under GA performed worse in every aspect.

We observed no influence of anesthesia regimen on successful reperfusion rates. The number of passages was highest in the converted group and lowest in the CS-group. However, in the GA-group, periprocedural time to groin puncture was extended by an average of 10 minutes and the delay was not compensated by the MT procedure time. Retrospective studies have suggested that the time delay through intubation may lead to worse outcome. ${ }^{21}$ While patients undergoing MT under
CS had slightly lower NIHSS at admission (13 vs. 15 in median), the difference in clinical stroke severity continued and even increased with respect to NIHSS and mRS after 24 hours, at discharge, and at 3-month follow-up. Regression analysis showed that CS was independently associated with higher probability of good outcome and lower odds for mortality at 3 months adjusted to confounders like baseline NIHSS. Patients who converted from $\mathrm{CS}$ to $\mathrm{GA}$ also had better outcome than patients in the GA- group. Besides poorer clinical outcome, GA was associated with a longer hospital stay of 2 days.

The strengths of our study include the large study cohort prospectively collected from a nationwide multicenter registry. Our data therefore represent clinical decisions on sedation management and anesthesia regimen in daily life practice, outside clinical trials. We observed the same results for the whole cohort of LVO patients as well as for anterior circulation strokes. We were able to analyze detailed information on complications and clinical follow-up. Given that it is unlikely that evidence will be established from large clinical trials in the near future, our results provide further evidence based on observational data that patients benefit from CS compared to GA.

However, our study has some limitations. Our data are observational, non-randomized and non-controlled. Therefore, interpretation of the data is prone to bias. Underlying selection bias for decision for an anesthesia regimen have to be discussed as well, even if individual variables in the patient baseline data did not differ. Individual clinical parameters, such as pmRS, NIHSS at admission or presence of tandem lesions, could have contributed to the decision for anesthesia regimens; however, we cannot analyze this in more detail retrospectively. Furthermore, we provide no information about the periprocedural use of sedative agents (type, dosage), further need of intensive care treatment, the duration of mechanical ventilation, and the reason for conversion from GA to CS. Apart from the vital signs at admission, there are no extensive data on the course of these vital signs and their impact on complications and outcome. Further, the CS-group also included patients who only received local anesthesia as a distinction between local anesthesia and CS was not made in the GSR-ET register.

\section{Conclusions}

Our study showed an influence on the functional and clinical outcome after MT by the choice of anesthesia regimen with advantages for CS compared to GA in terms of complications, functional outcome, and mortality. 


\section{Supplementary materials}

Supplementary materials related to this article can be found online at https://doi.org/10.5853/jos.2020.02404.

\section{Disclosure}

Thomas Liebig consults for Stryker Neurovascular $\mathrm{GmbH}$ and has received speaker honoraria from Pfizer, Covidien, Phenox, and Microvention outside this study.

Lars Kellert has received funding for travel or speaker honoraria from Bayer Vital, Boehringer Ingelheim, Bristol-MeyerSquibb, Daiichi Sankyo, and Pfizer outside of this study.

\section{Acknowledgments}

The authors thank Katie Göttlinger and J Stuart Lund for proofreading the manuscript.

\section{References}

1. Schönenberger $S$, Hendén $P L$, Simonsen $C Z$, Uhlmann $L$, Klose C, Pfaff JAR, et al. Association of general anesthesia vs procedural sedation with functional outcome among patients with acute ischemic stroke undergoing thrombectomy: a systematic review and meta-analysis. JAMA 2019;322:12831293.

2. Campbell BCV, van Zwam WH, Goyal M, Menon BK, Dippel DWJ, Demchuk AM, et al. Effect of general anaesthesia on functional outcome in patients with anterior circulation ischaemic stroke having endovascular thrombectomy versus standard care: a meta-analysis of individual patient data. Lancet Neurol 2018;17:47-53.

3. Cappellari M, Pracucci G, Forlivesi S, Saia V, Nappini S, Nencini $P$, et al. General anesthesia versus conscious sedation and local anesthesia during thrombectomy for acute ischemic stroke. Stroke 2020;51:2036-2044.

4. Wollenweber FA, Tiedt S, Alegiani A, Alber B, Bangard C, Berrouschot J, et al. Functional outcome following stroke thrombectomy in clinical practice. Stroke 2019;50:2500-2506.

5. Alegiani AC, Dorn F, Herzberg M, Wollenweber FA, Kellert $L$, Siebert $E_{1}$ et al. Systematic evaluation of stroke thrombectomy in clinical practice: the German stroke registry endovascular treatment. Int J Stroke 2019;14:372-380.

6. Ringleb PA, Hamann GF, Röther J, Jansen O, Groden C, Veltkamp R. Akuttherapie des ischämischen schlaganfalls: rekanalisierende therapie [Therapy of acute ischemic stroke: recanalisation therapy guideline]. Aktuelle Neurol 2016;43:82-91.
7. Turc G, Bhogal P, Fischer U, Khatri P, Lobotesis K, Mazighi M, et al. European Stroke Organisation (ESO)-European Society for Minimally Invasive Neurological Therapy (ESMINT) guidelines on mechanical thrombectomy in acute ischemic stroke. J Neurointerv Surg 2019;11:535-538.

8. Powers WJ, Rabinstein AA, Ackerson T, Adeoye OM, Bambakidis NC, Becker K, et al. 2018 Guidelines for the early management of patients with acute ischemic stroke: a guideline for healthcare professionals from the American Heart Association/ American Stroke Association. Stroke 2018;49:e46-e110.

9. Bekelis $K$, Missios S, MacKenzie TA, Tjoumakaris $S$, Jabbour P. Anesthesia technique and outcomes of mechanical thrombectomy in patients with acute ischemic stroke. Stroke 2017; 48:361-366.

10. Powers CJ, Dornbos D 3rd, Mlynash M, Gulati D, Torbey M, Nimjee SM, et al. Thrombectomy with conscious sedation compared with general anesthesia: a DEFUSE 3 analysis. AJNR Am J Neuroradiol 2019;40:1001-1005.

11. Shan W, Yang D, Wang H, Xu L, Zhang M, Liu W, et al. General anesthesia may have similar outcomes with conscious sedation in thrombectomy patients with acute ischemic stroke: a real-world registry in China. Eur Neurol 2018;80:7-13.

12. Goldhoorn RB, Bernsen MLE, Hofmeijer J, Martens JM, Lingsma HF, Dippel DWJ, et al. Anesthetic management during endovascular treatment of acute ischemic stroke in the MR CLEAN Registry. Neurology 2020;94:e97-e106.

13. Berkhemer $O A$, Fransen PS, Beumer $D$, van den Berg $L A$, Lingsma $\mathrm{HF}$, Yoo $\mathrm{A}$, et al. $A$ randomized trial of intraarterial treatment for acute ischemic stroke. N Engl J Med 2015;372: 11-20.

14. Flottmann $F$, Leischner $H$, Broocks $G$, Faizy TD, Aigner A, DebChatterji $\mathrm{M}$, et al. Emergency conversion to general anesthesia is a tolerable risk in patients undergoing mechanical thrombectomy. AJNR Am J Neuroradiol 2020;41:122-127.

15. Ren C, Xu G, Liu Y, Liu G, Wang J, Gao J. Effect of conscious sedation vs. general anesthesia on outcomes in patients undergoing mechanical thrombectomy for acute ischemic stroke: a prospective randomized clinical trial. Front Neurol 2020;11:170.

16. Schönenberger S, Uhlmann L, Hacke W, Schieber S, Mundiyanapurath $\mathrm{S}$, Purrucker JC, et al. Effect of conscious sedation vs general anesthesia on early neurological improvement among patients with ischemic stroke undergoing endovascular thrombectomy: a randomized clinical trial. JAMA 2016;316:1986-1996.

17. Simonsen CZ, Sørensen LH, Juul N, Johnsen SP, Yoo AJ, Andersen $G$, et al. Anesthetic strategy during endovascular therapy: general anesthesia or conscious sedation? (GOLIATH 
- General or Local Anesthesia in Intra Arterial Therapy): a single-center randomized trial. Int J Stroke 2016;11:10451052.

18. Petersen NH, Ortega-Gutierrez S, Wang A, Lopez GV, Strander $S$, Kodali $S$, et al. Decreases in blood pressure during thrombectomy are associated with larger infarct volumes and worse functional outcome. Stroke 2019;50:1797-1804.

19. Mundiyanapurath $S$, Stehr $A$, Wolf $M$, Kieser M, Möhlenbruch $M$, Bendszus $M$, et al. Pulmonary and circulatory parameter guided anesthesia in patients with ischemic stroke undergoing endovascular recanalization. J Neurointerv Surg
2016;8:335-341.

20. Kety SS, Schmidt CF. The effects of altered arterial tensions of carbon dioxide and oxygen on cerebral blood flow and cerebral oxygen consumption of normal young men. J Clin Invest 1948;27:484-492.

21. Brinjikji W, Murad MH, Rabinstein AA, Cloft HJ, Lanzino G, Kallmes DF. Conscious sedation versus general anesthesia during endovascular acute ischemic stroke treatment: a systematic review and meta-analysis. AJNR Am J Neuroradiol 2015;36:525-529. 
Appendix 1. GSR investigators

\begin{tabular}{|c|c|c|c|c|}
\hline Name & Degree & Organization & Role & Contribution \\
\hline Tobias Boeckh-Behrens & MD & Klinikum r.d.Isar, Munich, Germany & Site Investigator & German Stroke Registry - Steering Committee \\
\hline Silke Wunderlich & MD & Klinikum r.d.Isar, Munich, Germany & Site Investigator & German Stroke Registry - Steering Committee \\
\hline Arno Reich & MD & Uniklinik RWTH Aachen, Germany & Site Investigator & German Stroke Registry - Steering Committee \\
\hline Anastasios Mpotsaris & MD & Uniklinik RWTH Aachen, Germany & Site Investigator & German Stroke Registry - Steering Committee \\
\hline Martin Wiesmann & MD & Uniklinik RWTH Aachen, Germany & Site Investigator & German Stroke Registry - Steering Committee \\
\hline Ulrike Ernemann & MD & Tübingen University Hospital, Germany & Site Investigator & German Stroke Registry - Steering Committee \\
\hline Till-Karsten Hauser & MD & Tübingen University Hospital, Germany & Site Investigator & German Stroke Registry - Steering Committee \\
\hline Christian H Nolte & MD & Charite Campus Benjamin Franklin & Site Investigator & German Stroke Registry - Steering Committee \\
\hline Eberhard Siebert & MD & $\begin{array}{l}\text { Charité - Campus Benjamin Franklin und Campus } \\
\text { Charité Mitte, Berlin, Germany }\end{array}$ & Site Investigator & German Stroke Registry - Steering Committee \\
\hline Sarah Zweynert & MD & Charité - Campus Virchow Klinikum, Berlin, Germany & Site Investigator & German Stroke Registry - Steering Committee \\
\hline Georg Bohner & MD & Charité - Campus Virchow Klinikum, Berlin, Germany & Site Investigator & German Stroke Registry - Steering Committee \\
\hline Alexander Ludolph & MD & Sana Klinikum Offenbach, Germany & Site Investigator & German Stroke Registry - Steering Committee \\
\hline Karl-Heinz Henn & MD & Sana Klinikum Offenbach, Germany & Site Investigator & German Stroke Registry - Steering Committee \\
\hline Waltraud Pfeilschifter & MD & Uniklinik Frankfurt/ Main, Germany & Site Investigator & German Stroke Registry - Steering Committee \\
\hline Marlis Wagner & MD & Uniklinik Frankfurt/ Main, Germany & Site Investigator & German Stroke Registry - Steering Committee \\
\hline Joachim Röther & MD & Asklepios Klinik Altona, Hamburg, Germany & Site Investigator & German Stroke Registry - Steering Committee \\
\hline Bernd Eckert & MD & Asklepios Klinik Altona, Hamburg, Germany & Site Investigator & German Stroke Registry - Steering Committee \\
\hline Jörg Berrouschot & MD & Klinikum Altenburger Land, Altenburg, Germany & Site Investigator & German Stroke Registry - Steering Committee \\
\hline Albrecht Bormann & MD & Klinikum Altenburger Land, Altenburg, Germany & Site Investigator & German Stroke Registry - Steering Committee \\
\hline Anna Alegiani & MD & $\begin{array}{l}\text { University Medical Center Hamburg-Eppendorf, } \\
\text { Hamburg, Germany }\end{array}$ & Site Investigator & German Stroke Registry - Steering Committee \\
\hline Jens Fiehler & MD & $\begin{array}{l}\text { University Medical Center Hamburg-Eppendorf, } \\
\text { Hamburg, Germany }\end{array}$ & Site Investigator & German Stroke Registry - Steering Committee \\
\hline Fabian Flottmann & MD & $\begin{array}{l}\text { University Medical Center Hamburg-Eppendorf, } \\
\text { Hamburg, Germany }\end{array}$ & Site Investigator & German Stroke Registry - Steering Committee \\
\hline Christian Gerloff & MD & $\begin{array}{l}\text { University Medical Center Hamburg-Eppendorf, } \\
\text { Hamburg, Germany }\end{array}$ & Site Investigator & German Stroke Registry - Steering Committee \\
\hline Götz Thomalla & MD & $\begin{array}{l}\text { University Medical Center Hamburg-Eppendorf, } \\
\text { Hamburg, Germany }\end{array}$ & Site Investigator & German Stroke Registry - Steering Committee \\
\hline Elke Hattingen & MD & University Hospital Bonn, Germany & Site Investigator & German Stroke Registry - Steering Committee \\
\hline Gabor Petzold & MD & University Hospital Bonn, Germany & Site Investigator & German Stroke Registry - Steering Committee \\
\hline Sven Thonke & MD & Klinikum Hanau, Germany & Site Investigator & German Stroke Registry - Steering Committee \\
\hline Christopher Bangard & MD & Klinikum Hanau, Germany & Site Investigator & German Stroke Registry - Steering Committee \\
\hline Christoffer Kraemer & MD & Klinikum Lüneburg, Germany & Site Investigator & German Stroke Registry - Steering Committee \\
\hline Martin Dichgans & MD & Ludwig Maximilian University of Munich, Germany & Site Investigator & German Stroke Registry - Steering Committee \\
\hline Marios Psychogios & MD & Georg-August-Universität Göttingen, Germany & Site Investigator & German Stroke Registry - Steering Committee \\
\hline Jan Liman & MD & Georg-August-Universität Göttingen, Germany & Site Investigator & German Stroke Registry - Steering Committee \\
\hline Martina Petersen & MD & Klinikum Osnabrück, Germany & Site Investigator & German Stroke Registry - Steering Committee \\
\hline Florian Stögbauer & MD & Klinikum Osnabrück, Germany & Site Investigator & German Stroke Registry - Steering Committee \\
\hline Peter Kraft & MD & University Hospital Würzburg, Germany & Site Investigator & German Stroke Registry - Steering Committee \\
\hline Mirko Pham & MD & University Hospital Würzburg, Germany & Site Investigator & German Stroke Registry - Steering Committee \\
\hline Michael Braun & MD & Bezirkskrankenhaus Günzburg, Germany & Site Investigator & German Stroke Registry - Steering Committee \\
\hline Gerhard F. Hamann & MD & Bezirkskrankenhaus Günzburg, Germany & Site Investigator & German Stroke Registry - Steering Committee \\
\hline Andreas Kastrup & MD & Klinikum Bremen Mitte, Germany & Site Investigator & German Stroke Registry - Steering Committee \\
\hline Christian Roth & MD & Klinikum Bremen Mitte, Germany & Site Investigator & German Stroke Registry - Steering Committee \\
\hline Klaus Gröschel & MD & University Medical Center Mainz, Germany & Site Investigator & German Stroke Registry - Steering Committee \\
\hline Timo Uphaus & MD & University Medical Center Mainz, Germany & Site Investigator & German Stroke Registry - Steering Committee \\
\hline Volker Limmroth & MD & Kliniken Köln, Germany & Site Investigator & German Stroke Registry - Steering Committee \\
\hline
\end{tabular}


Supplementary Table 1. Characteristics of GSR patients with anterior circulation stroke comparing the anesthesia regimen ( $n=5,808$ patients, unknown in $n=256)$

\begin{tabular}{|c|c|c|c|c|}
\hline Characteristic & $\begin{array}{c}\text { Conscious sedation } \\
(n=1,572,27.1 \%)\end{array}$ & $\begin{array}{c}\text { General anesthesia } \\
(\mathrm{n}=3,786,65.2 \%)\end{array}$ & $\begin{array}{c}\text { Conversion } \\
(n=194,3.3 \%)\end{array}$ & $P$ \\
\hline Age (yr) & $73.4 \pm 13.0$ & $73.4 \pm 13.0$ & $72.0 \pm 12.8$ & 0.168 \\
\hline Female sex & 799 (50.8) & $1,984(52.4)$ & $98(50.5)$ & 0.516 \\
\hline \multicolumn{5}{|l|}{ Clinical characteristics at admission } \\
\hline pmRS & $\begin{array}{c}0(0-1) \\
\text { (missing in } n=42)\end{array}$ & $\begin{array}{c}0(0-1) \\
\text { (missing in } n=281)\end{array}$ & $\begin{array}{c}0(0-1) \\
\text { (missing in } n=13)\end{array}$ & 0.014 \\
\hline $\mathrm{pmRS} \leq 1$ & $1,222(77.7)$ & $2,737(72.3)$ & $150(77.3)$ & 0.002 \\
\hline Baseline NIHSS & $14(9-17)$ & $15(10-19)$ & $15(10-19)$ & $<0.001$ \\
\hline Drip and ship & $773(49.2)$ & $1,564(41.3)$ & $94(48.5)$ & $<0.001$ \\
\hline Admission BP systolic & $154.4 \pm 27.5$ & $151.1 \pm-27.2$ & $154.1 \pm 27.6$ & $<0.001$ \\
\hline Admission BP diastolic & $84.1 \pm 16.9$ & $82.2 \pm 16.8$ & $85.6 \pm 15.9$ & $<0.001$ \\
\hline Admission heartrate & $81.9 \pm 18.2$ & $81.9 \pm 19.4$ & $84.3 \pm 18.7$ & 0.111 \\
\hline OAC at admission & $315(20.0)$ & $787(20.8)$ & $32(16.5)$ & 0.067 \\
\hline \multicolumn{5}{|l|}{ Risk factors } \\
\hline Arterial hypertension & $1,165(74.1)$ & $2,774(73.3)$ & $139(71.6)$ & 0.004 \\
\hline Diabetes mellitus & $326(20.7)$ & $792(20.9)$ & $42(21.6)$ & 0.459 \\
\hline Hypercholesterolemia & $512(32.6)$ & $1,509(39.9)$ & $69(35.6)$ & $<0.001$ \\
\hline Current smoking & $197(12.5)$ & $513(13.5)$ & 35 (18.0) & $<0.001$ \\
\hline Atrial fibrillation & $637(40.5)$ & $1,550(40.9)$ & $74(38.1)$ & 0.082 \\
\hline \multicolumn{5}{|l|}{ Imaging data } \\
\hline ASPECTS & $9(7-10)$ & $9(7-10)$ & $8(7-10)$ & 0.010 \\
\hline Tandem lesion & $216(13.7)$ & $598(15.8)$ & $37(19.1)$ & 0.020 \\
\hline Right-sided occlusion & $791(50.3)$ & $1,728(45.7)$ & $85(43.8)$ & 0.001 \\
\hline \multicolumn{5}{|l|}{ Time intervals (min) } \\
\hline Admission to groin & $60.0(39.0-88.0)$ & $70.0(47.0-100.0)$ & $60.0(41.0-81.0)$ & $<0.001$ \\
\hline Groin to flow restoration & $39.0(25.0-63.0)$ & $41.0(26.0-65.0)$ & $64.0(42.0-100.0)$ & $<0.001$ \\
\hline Admission to flow restoration & $106.0(75.0-142.0)$ & $118.0(88.0-159.0)$ & $129.0(97.0-179.0)$ & $<0.001$ \\
\hline \multicolumn{5}{|l|}{ Treatment } \\
\hline IVT treatment & $809(51.5)$ & $1,910(50.4)$ & $121(62.4)$ & 0.005 \\
\hline $\begin{array}{l}\text { Additive medication during } \\
\text { thrombectomy }\end{array}$ & 313 (19.9) & $1,305(34.5)$ & $44(22.7)$ & $<0.001$ \\
\hline ASA & $16(1.0)$ & $84(2.2)$ & $5(2.6)$ & 0.010 \\
\hline Clopidogrel & $2(0.1)$ & $11(0.3)$ & $1(0.5)$ & 0.420 \\
\hline Ticagrelor & $0(0)$ & $16(0.4)$ & $1(0.5)$ & 0.034 \\
\hline Tirofiban & $18(1.1)$ & $84(2.2)$ & $8(4.1)$ & 0.003 \\
\hline Abciximab & $12(0.8)$ & $0(0)$ & $0(0)$ & 1.000 \\
\hline Heparin & $218(13.9)$ & $912(24.1)$ & $24(12.4)$ & $<0.001$ \\
\hline rtPA & $43(2.7)$ & $78(2.1)$ & $6(3.1)$ & 0.239 \\
\hline $\begin{array}{l}\text { Acute treatment ipsilateral ICA } \\
\text { (stenting and/or PTA) }\end{array}$ & $167(10.6)$ & $526(13.9)$ & $25(12.9)$ & 0.015 \\
\hline No. of passages & $2.0 \pm 1.6$ & $2.2 \pm 1.9$ & $2.5 \pm 1.9$ & $<0.001$ \\
\hline Periprocedural complications & $230(14.6)$ & $802(21.2)$ & $57(29.4)$ & $<0.001$ \\
\hline Device malfunction & $8(0.5)$ & $18(0.5)$ & $2(1.0)$ & 0.557 \\
\hline Dissection, perforation & $41(2.6)$ & $105(2.8)$ & $11(5.7)$ & 0.049 \\
\hline Clot migration, embolization & $54(3.4)$ & $154(4.1)$ & $9(4.6)$ & 0.480 \\
\hline $\mathrm{ICH}$ & $29(1.8)$ & $111(2.9)$ & $12(6.2)$ & $<0.001$ \\
\hline
\end{tabular}


Supplementary Table 1. Continued

\begin{tabular}{|c|c|c|c|c|}
\hline Characteristic & $\begin{array}{l}\text { Conscious sedation } \\
(\mathrm{n}=1,572,27.1 \%)\end{array}$ & $\begin{array}{c}\text { General anesthesia } \\
(\mathrm{n}=3,786,65.2 \%)\end{array}$ & $\begin{array}{c}\text { Conversion } \\
(n=194,3.3 \%)\end{array}$ & $P$ \\
\hline Vasospasm & $56(3.6)$ & $344(9.1)$ & $20(10.3)$ & $<0.001$ \\
\hline Other & $108(6.9)$ & $220(5.8)$ & $22(11.3)$ & 0.005 \\
\hline Successful reperfusion $\mathrm{mTICl} 2 \mathrm{~b} / 3$ & $1,303(82.9)$ & $3,192(84.3)$ & $162(83.5)$ & 0.117 \\
\hline \multicolumn{5}{|l|}{ 24-hr Follow-up } \\
\hline $\mathrm{mRS}$ & $\begin{array}{c}4(3-5) \\
\text { (missing in } n=86)\end{array}$ & $\begin{array}{c}5(3-5) \\
\text { (missing in } n=411)\end{array}$ & $\begin{array}{c}5(4-5) \\
\text { (missing in } n=29)\end{array}$ & $<0.001$ \\
\hline NIHSS & $8(4-16)$ & $11(5-19)$ & $14(5-22)$ & $<0.001$ \\
\hline Complications & $682(43.4)$ & $1,765(46.6)$ & $103(53.1)$ & 0.012 \\
\hline $\begin{array}{l}\text { Malignant middle cerebral artery } \\
\text { infarction }\end{array}$ & $67(4.3)$ & $278(7.3)$ & $15(7.7)$ & $<0.001$ \\
\hline Recurrent stroke & $56(3.6)$ & $203(5.4)$ & $4(2.1)$ & 0.004 \\
\hline $\mathrm{ICH}$ & $184(11.7)$ & $669(15.0)$ & $44(22.7)$ & $<0.001$ \\
\hline Groin haematoma & $34(2.2)$ & $55(1.5)$ & $7(3.6)$ & 0.384 \\
\hline Groin aneurysma & $14(0.9$ & $26(0.7)$ & $1(0.5)$ & 0.381 \\
\hline Other complications & $412(26.2)$ & $1,055(27.9)$ & $61(31.4)$ & 0.104 \\
\hline Hospital stay & $9.5 \pm 7.4$ & $11.3 \pm 9.7$ & $11.2 \pm 8.3$ & $<0.001$ \\
\hline Discharge & & & & 0.561 \\
\hline $\mathrm{mRS}$ & $\begin{array}{c}4(2-5) \\
\text { (missing in } n=17)\end{array}$ & $\begin{array}{c}4(2-5) \\
\text { (missing in } n=274)\end{array}$ & $\begin{array}{c}4(2-5) \\
\text { (missing in } n=9)\end{array}$ & $<0.001$ \\
\hline NIHSS & $4(1-11)$ & $5(2-12)$ & $6(2-13)$ & 0.024 \\
\hline Mortality (mRS 6) & $180(11.5)$ & 625 (16.5) & 22 (12.0) & $<0.001$ \\
\hline
\end{tabular}

Values are presented as mean \pm standard deviation, number (\%), or median (interquartile range).

GSR, German Stroke Registry; pmRS, pre-stroke modified Rankin Scale; NIHSS, National Institutes of Health Stroke Scale; BP, blood pressure; OAC, oral anticoagulation; ASPECTS, Alberta Stroke Program Early CT Score; IVT, intravenous thrombolysis; ASA, acetylsalicylic acid; rtPA, recombinant tissue plasminogen activator; ICA, internal carotid artery; PTA, percutaneous transluminal angioplasty; ICH, intracerebral hemorrhage; mTICl, modified thrombolysis in cerebral infarction; mRS, modified Rankin Scale. 
Supplementary Table 2. Logistic regression for good outcome in anterior circulation stroke patients at follow-up

\begin{tabular}{lccc}
\hline Variable & OR & $95 \% \mathrm{Cl}$ & \multicolumn{1}{c}{$P$} \\
Age & 0.95 & $0.95-0.96$ & $<.001$ \\
Sex & 0.99 & $0.84-1.15$ & $<.859$ \\
pmRS & 0.51 & $0.47-0.56$ & $<0.001$ \\
NIHSS at admission & 0.88 & $0.86-0.89$ & $<0.001$ \\
Treatment with IVT & 1.57 & $1.35-1.84$ & $<0.001$ \\
Successful reperfusion (mTICl 2b/3) & 5.41 & $4.15-7.05$ & $<0.001$ \\
General anesthesia & 0.86 & $0.74-0.99$ & 0.041 \\
ICH & 0.25 & $0.20-0.31$ & $<0.001$ \\
Time groin to flow restoration & 0.99 & $0.99-1.00$ & 0.009 \\
\hline
\end{tabular}

$\mathrm{OR}$, odds ratio; $\mathrm{Cl}$, confidence interval; pmRS, pre-stroke modified Rankin Scale; NIHSS, National Institutes of Health Stroke Scale; IVT, intravenous thrombolysis; $\mathrm{mTICl}$, modified thrombolysis in cerebral infarction; $\mathrm{ICH}$, intracerebral hemorrhage.

Supplementary Table 3. Logistic regression for mortality in anterior circulation stroke patients at follow-up

\begin{tabular}{lccc}
\hline Variable & OR & $95 \% \mathrm{Cl}$ & \multicolumn{1}{c}{$P$} \\
\hline Age & 1.07 & $1.06-1.07$ & 0.001 \\
Sex & 0.88 & $0.75-1.04$ & $<.126$ \\
pmRS & 1.37 & $1.29-1.46$ & $<.001$ \\
NIHSS at admission & 1.10 & $1.09-1.12$ & $<0.001$ \\
Treatment with IVT & 0.67 & $0.57-0.79$ & $<0.001$ \\
Successful reperfusion (mTICl 2b/3) & 0.28 & $0.23-0.34$ & $<0.001$ \\
General anesthesia & 1.38 & $1.19-1.61$ & $<0.001$ \\
ICH & 2.73 & $2.26-3.31$ & $<0.001$ \\
Time admission to groin & 1.00 & $1.00-1.00$ & 0.323
\end{tabular}

$\mathrm{OR}$, odds ratio; $\mathrm{Cl}$, confidence interval; pmRS, pre-stroke modified Rankin Scale; NIHSS, National Institutes of Health Stroke Scale; IVT, intravenous thrombolysis; $\mathrm{mTICl}$, modified thrombolysis in cerebral infarction; ICH, intracerebral hemorrhage. 